\title{
A structure analysis of Chinese iron and steel industry based on Jingyou evaluation of performances of listed companies
}

\author{
Xinan Zhao ${ }^{1, \mathrm{a}}$, Jongho Kim²,b Gyongsu Pak ${ }^{3}$ \\ ${ }^{1}$ School of Business Administration, Northeastern University, Shenyang, China \\ ${ }^{2}$ School of Business Administration, Northeastern University, Shenyang, China \\ ${ }^{3}$ Institute of Science Strategy, State Academy of Sciences, Pyongyang, DPRK
}

\begin{abstract}
With the value ideology of modern strategic management, a new industrial structure analysis method was proposed based on the Jingyou theory rather than the traditional competitive mechanism in this paper, and then it was carried out to apply it to the performance data of the listed companies in the first quarter of 2017 in order to explain the structural feature of Chinese iron and steel industry. Such analysis results as the distributive feature of enterprise groups in industry, the main developing mode of industry, the identification of benchmarks and partners will be helpful to the detailed explanation of structural feature of industry under the objective law of development of things and contribute to solve some important problems in the modern corporate strategic management practice.
\end{abstract}

\section{INTRODUCTION}

Industrial structure analysis refers to the in-depth analysis of industrial operation by the analytic tools to discover its inherent economic law and predict its future development. The SCP framework [1], the five-force model [2], the value chain analysis [3] and the strategic group analysis have been widely used [4-7]. These methods provided the detailed information about the competitive situation and structure so that could play an important role in the practice of strategic management such as the making of competitive strategy, the establishment of competitive advantage, the cultivation of core ability and so on.

Entering the 21st century, the great changes have taken place in all aspects of human society and economic life. [8] put forward "Theory of decline of competition", in which he proposed a new concept of "commercial ecosystem", which made it possible to break the limitation of strategic management based on competition and to seek "co-evolution". As the competition is no longer regarded as to a driving force for development, the value ideology of strategic management is being evolved from the competition to the innovation and collaboration. [9] suggested the Jingyou idea. They explained that people should strive to explore and use natural laws to exhibit their beings in the improvement of environment and the creation of benefits for mankind, which were named "Jingyou". Jingyou argues that the exhibition of individual advantage must be maximized on the principle of combining it with group's benefit. [9] also proposed the Jingyou evaluation theory based on
Jingyou idea, which came from the demand for analysis and management of Jingyou behaviors of individuals in group and would quite be consistent with the objective law of development of things and the value ideology of modern corporate strategic management.

The industrial structure is a basis for determining corporate behavior and performance in industry, while the performance is a result of behavior, so that it is possible to understand the corporate behaviors and structural feature in industry through the analysis of the performances of listed companies in an industry. The purpose of this study is to establish an industrial structure analysis method based on Jingyou evaluation theory and then to explain the structural feature of Chinese iron and steel industry through its application to the performance data of the listed companies in the first quarter of 2017.

Figure 1 shows the basic framework of method.

axnzhao@mail.neu.edu.cn, ${ }^{b}$ kimjongho@163.com 


\section{METHOD}

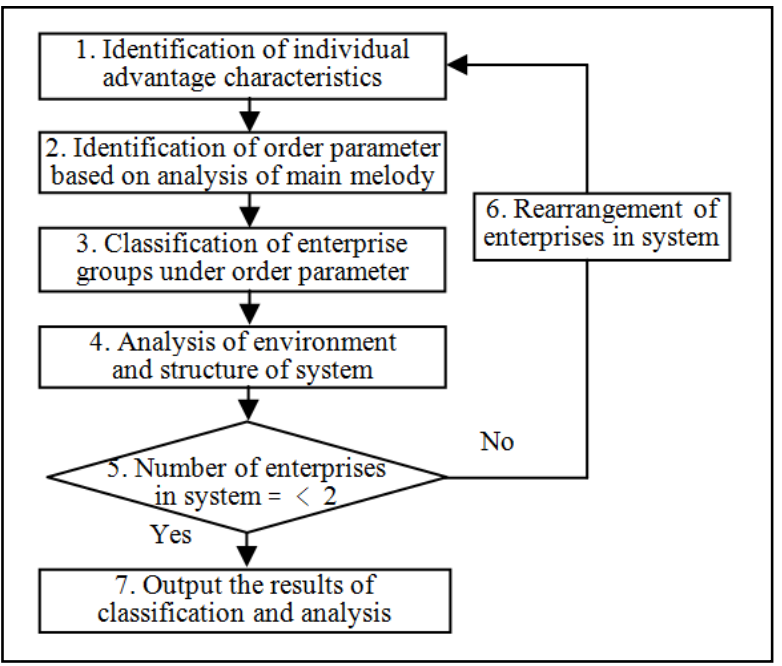

Figure. 1. The basic framework of method

From the standpoint of the system dynamics, either industry or enterprise may be regarded as to a system because they are all self-organized systems.

\subsection{Step 1: Identification of Individual Advantage Characteristics}

The individual advantage characteristic is an essential structure which corresponds to the index system which can best reflect the corporate behavior under industrial environment. In this paper, an ideal point utility model is used to identify characteristics of individual advantage [9];

$$
\min _{w} d^{2}\left(f_{i}, \tilde{f}\right)=\sum_{j=1}^{m} w_{i j}^{2}\left(f_{j}\left(x_{i}\right)-\tilde{f}_{j}\right)^{2}=\sum_{i j}^{m} w_{i j}^{2}\left(f_{i j}-\tilde{f}\right)^{2}
$$

s.t. $\sum_{j=1}^{m} w_{i j}=1, w_{i j} \geq 0, j=1,2, \ldots, m i=1,2, \ldots, n$

where $m$ is the number of indices and $n$ is the number of enterprises, $w_{i}{ }^{*}=\left(w^{*}{ }_{i 1}, w^{*}{ }_{i 2}, \ldots, w^{*}{ }_{i m}\right)^{\tau}$, which is the optimal solution of equation (1), represents the value structure of individual advantage characteristic of $x_{i}$.

\subsection{Step 2: Identification of Order Parameter}

The industry is a group of enterprises, where are several enterprise groups, the classification of which is also possible. The enterprises may be integrated into groups with the different advantage distribution characteristics by cluster analysis, among which the groups composed of more than $20 \%$ of all members in system are considered as the representative ones of system by Pareto principle [9].

An acceptable value structure for all enterprises in system can be obtained by equation (2).

$$
w^{*}=\frac{1}{n} \sum_{i=1}^{n} w_{i}^{*}
$$

It is also possible to calculate the common value structure of $k$-th group by using equation (2). By substituting the result of equation (2) into (3), it is possible to obtain the utility of each enterprise $D\left(x_{k}\right)$ and its ranking order $G\left(x_{k}\right)$ under $w^{*}$.

$$
\begin{aligned}
d_{w_{i}^{*}}\left(f_{k}, \tilde{f}\right) & =\sqrt{\sum_{j=1}^{m} w_{i j}^{* 2}\left(\tilde{f}_{j}-f_{k j}\right)^{2}} \\
i, k & =1,2, \ldots, n
\end{aligned}
$$

There will be only an order parameter that determines its evolutionary development in system. The order parameter is a macroscopic parameter that reflects the kinematic mode of a system, while the value structure can be used for a concrete manifestation of order parameter because it has the same function and role, i.e., the order parameter plays a guiding and restraining role through the value structure in system. If $G_{R}^{*}$ is a vector of ranking orders of enterprises under $w^{*}$ and $G_{k}$ is that under the common value structure of $k$-th representative group, the deviation between $G_{R}^{*}$ and $G_{k}$ may be expressed as follows:

$$
E_{R k}=\frac{1}{\beta} \sum_{i=1}^{n}\left|G_{R i}^{*}-G_{k i}\right|
$$

where $\beta$ is a deviation coefficient. The similarity $C_{R k}$ between $G_{R}^{*}$ and $G_{k}$ is as follows:

$$
C_{R k}=\frac{1}{1+E_{R k}}
$$

The value structure with the largest $C_{R k}$ is just an order parameter of the system.

\subsection{Step 3: Classification of Enterprise Groups}

The clustered number under order parameter is used to classify the groups because there is only one order parameter in a system. Each classification produces the corresponding layer.

\subsection{Step 4: Structural Analysis of System}

- The representative group that has an order parameter is just the mainstream group of system, which may be classified into advantageous or inferior one according to its degree of impact on system. If most of enterprises that occupy $0.2 \times n$ th or higher orders in $G_{R}^{*}$ (advantageous enterprises) are involved in a mainstream group (MG), the group belongs to advantageous, otherwise, it is inferior. In addition, it is possible to understand the situation of distribution of 
group or enterprise from the multi-layer structure of industry.

- $\quad$ There will be an order parameter corresponding to each layer of industrial structure, so the main developing mode of system can be determined by analyzing its value parameter structure.

- The enterprises which occupy $0.2 \times n$-th or higher orders in $G_{R}^{*}$ are the benchmarks of other enterprises in the group [9], while the enterprises in a group will become partners to each other.

\subsection{Step 5: Judgment to Continue or Stop the Classification}

The steps from 1 to 4 can be repeated according to the result of step 5, i.e., if the number of enterprises in a system is 2 or less, the Steps 3 and 4 should be stopped and transferred to Step 7. Otherwise, they should be transferred to Step 1 through Step 6.

\subsection{Step 6: Rearrangement of Enterprises in System}

The other enterprises except the enterprises already classified are all re-arranged in the system.

\subsection{Step 7: Output of the Results of Classification and Analysis}

It is possible to obtain the ordered layer structure and the corresponding analysis results whenever each classification is performed.

\section{STRUCTURE ANALYSIS OF CHINESE IRON AND STEEL INDUSTRY}

Tables I, II, III and IV describe the performance index of 41 listed companies in Chinese iron and steel in the first quarter of 2017 and the Jingyou evaluation results for their performances.

TABLE I: THE PERFORMANCE INDEX

\begin{tabular}{|c|c|c|c|}
\hline $\begin{array}{l}\mathrm{N} \\
\mathrm{O}\end{array}$ & Indicator of Evaluation & $\begin{array}{l}\mathrm{N} \\
\mathrm{O}\end{array}$ & Indicator of Evaluation \\
\hline 1 & Earnings per share $(\mathrm{RMB}), w_{1}$ & 5 & Rate of return on common \\
\hline 2 & Gross sales (RMB), $w_{2}$ & 6 & $\begin{array}{l}\text { Cash flow from operations } \\
\text { per share (RMB), } w_{6}\end{array}$ \\
\hline 3 & Net profit $(\mathrm{RMB}), w_{3}$ & 7 & Gross profit ratio $(\%), w_{7}$ \\
\hline 4 & Net assets per share (RMB), $w_{4}$ & & \\
\hline
\end{tabular}

TABLE II: THE INDIVIDUAL ADVANTAGE CHARACTERISTICS FOR THE PERFORMANCE OF 41 LISTED COMPANIES

\begin{tabular}{|l|l|l|l|l|l|l|l|}
\hline $\mathrm{LC}$ & $w_{1}$ & $w_{2}$ & $w_{3}$ & $w_{4}$ & $w_{5}$ & $w_{6}$ & $w_{7}$ \\
\hline 1 & 0.0847 & 0.0880 & 0.0847 & 0.0847 & 0.0847 & 0.4887 & 0.0847 \\
2 & 0.0584 & 0.0222 & 0.0286 & 0.1834 & 0.4917 & 0.1689 & 0.0468 \\
3 & 0.0834 & 0.0261 & 0.0406 & 0.2428 & 0.4305 & 0.1176 & 0.059 \\
4 & 0 & 0.5 & 0.5 & 0 & 0 & 0 & 0 \\
5 & 0.0778 & 0.0196 & 0.0291 & 0.0265 & 0.669 & 0.117 & 0.0609 \\
6 & 1 & 0 & 0 & 0 & 0 & 0 & 0 \\
7 & 0.0488 & 0.0188 & 0.0251 & 0.0317 & 0.4987 & 0.3251 & 0.0519 \\
8 & 0.0712 & 0.0269 & 0.0394 & 0.0377 & 0.5487 & 0.218 & 0.0581 \\
9 & 0.0573 & 0.0255 & 0.0252 & 0.0297 & 0.5242 & 0.2978 & 0.0403 \\
10 & 0.0484 & 0.0237 & 0.034 & 0.026 & 0.6315 & 0.1265 & 0.1099 \\
11 & 0.0477 & 0.0324 & 0.0371 & 0.0376 & 0.6018 & 0.1727 & 0.0707 \\
12 & 0.3814 & 0.0071 & 0.0106 & 0.0551 & 0.2182 & 0.3019 & 0.0258 \\
13 & 0 & 0 & 0 & 0 & 0 & 1 & 0 \\
14 & 0.0013 & 0.0003 & 0.0004 & 0.9901 & 0.0069 & 0.0003 & 0.0008 \\
15 & 0.0683 & 0.0281 & 0.0335 & 0.0384 & 0.711 & 0.077 & 0.0438 \\
16 & 0.0827 & 0.0315 & 0.0377 & 0.0934 & 0.6544 & 0.0238 & 0.0765
\end{tabular}




\begin{tabular}{|l|l|l|l|l|l|l|l|}
17 & 0.0508 & 0.0279 & 0.0336 & 0.0341 & 0.6157 & 0.1115 & 0.1264 \\
18 & 0.0638 & 0.0278 & 0.0334 & 0.1159 & 0.5019 & 0.1786 & 0.0787 \\
19 & 0.0558 & 0.0333 & 0.0343 & 0.0785 & 0.5552 & 0.1802 & 0.0627 \\
20 & 0.0478 & 0.0232 & 0.0305 & 0.0349 & 0.5866 & 0.1645 & 0.1126 \\
21 & 0.035 & 0.0183 & 0.024 & 0.0404 & 0.4305 & 0.1002 & 0.3516 \\
22 & 0 & 0 & 0 & 0 & 1 & 0 & 0 \\
23 & 0.0453 & 0.0244 & 0.0324 & 0.0559 & 0.5718 & 0.1875 & 0.0829 \\
24 & 0.0485 & 0.0249 & 0.0332 & 0.0528 & 0.6028 & 0.1124 & 0.1254 \\
25 & 0 & 0 & 0 & 1 & 0 & 0 & 0 \\
26 & 0.0439 & 0.0278 & 0.037 & 0.0551 & 0.5995 & 0.1718 & 0.0649 \\
27 & 0.0383 & 0.0283 & 0.0371 & 0.0486 & 0.5456 & 0.178 & 0.1241 \\
28 & 0.022 & 0.0089 & 0.0119 & 0.6563 & 0.217 & 0.0492 & 0.0347 \\
29 & 0 & 0 & 0 & 0 & 0 & 0 & 1 \\
30 & 0.0464 & 0.025 & 0.0334 & 0.0515 & 0.5884 & 0.1933 & 0.062 \\
31 & 0.0352 & 0.028 & 0.0366 & 0.0851 & 0.575 & 0.1955 & 0.0446 \\
32 & 0.0383 & 0.0196 & 0.0262 & 0.0467 & 0.4714 & 0.0908 & 0.3071 \\
33 & 0.0576 & 0.029 & 0.0325 & 0.1165 & 0.548 & 0.1675 & 0.0489 \\
34 & 0.0526 & 0.0272 & 0.036 & 0.0914 & 0.6456 & 0.081 & 0.0662 \\
35 & 0.0573 & 0.0255 & 0.0252 & 0.0297 & 0.5242 & 0.2978 & 0.0403 \\
36 & 0.099 & 0.0092 & 0.0136 & 0.0164 & 0.4534 & 0.2999 & 0.1085 \\
37 & 0.0001 & 0.0001 & 0.0001 & 0.0003 & 0.0015 & 0.0005 & 0.9974 \\
38 & 0.0315 & 0.0263 & 0.0229 & 0.0489 & 0.3038 & 0.5305 & 0.036 \\
39 & 0.0673 & 0.0243 & 0.0294 & 0.0498 & 0.5516 & 0.2343 & 0.0432 \\
40 & 0.0433 & 0.0199 & 0.0266 & 0.0509 & 0.4917 & 0.0796 & 0.2879 \\
41 & 0.047 & 0.0204 & 0.027 & 0.0276 & 0.5837 & 0.225 & 0.0693 \\
\hline
\end{tabular}

(LC is an abbreviation of listed company.)

TABLE III: THE EVALUATION OF UTILITY UNDER $w^{*}$

\begin{tabular}{|l|l|l|l|l|l|l|l|}
\hline LC & $G_{k}$ & LC & $G_{k}$ & LC & $G_{k}$ & LC & $G_{k}$ \\
\hline 1 & 41 & 12 & 1 & 23 & 25 & 34 & 36 \\
2 & 12 & 13 & 32 & 24 & 28 & 35 & 16 \\
3 & 6 & 14 & 39 & 25 & 5 & 36 & 2 \\
4 & 3 & 15 & 37 & 26 & 35 & 37 & 9 \\
5 & 14 & 16 & 40 & 27 & 34 & 38 & 8 \\
6 & 4 & 17 & 27 & 28 & 11 & 39 & 18 \\
7 & 19 & 18 & 7 & 29 & 13 & 40 & 23 \\
8 & 10 & 19 & 17 & 30 & 29 & 41 & 24 \\
9 & 15 & 20 & 26 & 31 & 38 & & \\
10 & 31 & 21 & 21 & 32 & 22 & & \\
11 & 30 & 22 & 33 & 33 & 20 & & \\
\hline
\end{tabular}

TABLE IV: THE RESULT OF CLASSIFICATION OF ENTERPRISE GROUPS

\begin{tabular}{|l|l|l|}
\hline Layer & \multicolumn{2}{|l|}{ Order parameter and Enterprise groups } \\
\hline \multirow{4}{*}{1 st } & Order parameter & $4 w_{1}=(0.0578,0.0365,0.0417,0.1261,0.4874,0.1693,0.0813)^{\tau}$ \\
& G1(MG) & $28,25,14,4,12,38,1,22,21,40,32,3,2,34,16,15,5,10,24,17,27,2$ \\
& G 4 & $0,30,23,26,11,41,39,8,18,33,31,19,36,7,35,9$ \\
\hline
\end{tabular}




\begin{tabular}{|c|c|c|}
\hline 2nd & $\begin{array}{l}\text { Order parameter } \\
\text { G } 1.1 \\
\text { G } 1.2(\mathbf{M G )} \\
\text { G } 1.3 \\
\text { G } 1.4\end{array}$ & $\begin{array}{l}5 w_{2}=(0.0524,0.0201,0.0255,0.0555,0.4866,0.2531,0.1068)^{\tau} \\
12,38,36,1,7,35,9 \\
22,5,16,34,15,10,24,17,27,20,3,18,2,33,23,19,31,30,26,11,4 \\
1,39,8 \\
28,25,14 \\
21,40,32\end{array}$ \\
\hline $3 \mathrm{rd}$ & $\begin{array}{l}\text { Order parameter } \\
\text { G } 1.1 .1 \\
\text { G } 1.1 .2 \\
\text { G } 1.2 .1(\mathbf{M G )} \\
\text { G } 1.2 .2\end{array}$ & $\begin{array}{l}3 w_{1}=(0.1382,0.0646,0.0318,0.0919,0.0155,0.6117,0.0462)^{\tau} \\
38,12,1 \\
36,7,35,9 \\
5,3,16,15,34,2,19,33,26,23,18,11,31,30,41,39,8 \\
27,24,17,20,10\end{array}$ \\
\hline 4th & $\begin{array}{l}\text { Order parameter } \\
\text { G } 1.1 .2 .1 \\
\text { G } 1.1 .2 .2 \\
\text { G } 1.2 .1 .1 \text { (MG) } \\
\text { G } 1.2 .2 .1\end{array}$ & $\begin{array}{l}3 w_{1}=(0.0861,0.0652,0.0335,0.0737,0.0343,0.6250,0.0822)^{\tau} \\
36,7 \\
35,9 \\
3,16,34,15,19,2,23,33,26,11,31,30,41,39,8 \\
17,20,24,27\end{array}$ \\
\hline 5 th & $\begin{array}{l}\text { Order parameter } \\
\text { G 1.2.1.1.1(MG) } \\
\text { G } 1.2 .1 .1 .2 \\
\text { G } 1.2 .2 .1 .1 \\
\end{array}$ & $\begin{array}{l}3 w_{1}=(0.0234,0.0451,0.0103,0.0504,0.0698,0.7422,0.0586)^{\tau} \\
19,2,39,11,33,26,41,31,30 \\
23,16,34,3 \\
17,20,27\end{array}$ \\
\hline 6th & $\begin{array}{l}\text { Order parameter } \\
\text { G 1.2.1.1.1.1 } \\
\text { G } 1.2 .2 .1 .1 .1 \\
\end{array}$ & $\begin{array}{l}2 w_{1}=(0.1564,0.1329,0.1447,0.1165,0.1124,0.1172,0.2100)^{\tau} \\
39,19,41,33,31,11,30,26 \\
23,3,34\end{array}$ \\
\hline 7 th & $\begin{array}{l}\text { Order parameter } \\
\text { G } \\
\text { 1.2.1.1.1.1(MG) } \\
\text { G } 1.2 .2 .1 .1 .1 .1 \\
\end{array}$ & $\begin{array}{l}2 w_{1}=(0.1506,0.1364,0.1455,0.0521,0.1357,0.1254,0.2543)^{\tau} \\
39,19,41,11,30,26 \\
33,31\end{array}$ \\
\hline 8th & $\begin{array}{l}\text { Order parameter } \\
\text { G } \\
\text { 1.2.1.1.1.1.1(MG } \\
\text { ) }\end{array}$ & $\begin{array}{l}2 w_{1}=(0.0641,0.1626,0.1619,0.1860,0.1706,0.0731,0.1815)^{\tau} \\
19,41,11,30,26\end{array}$ \\
\hline 9th & $\begin{array}{l}\text { Order parameter } \\
\text { G } \\
\text { 1.2.1.1.1.1.1.1(M } \\
\text { G) }\end{array}$ & $\begin{array}{l}2 w_{1}=(0.1640,0.1800,0.1791,0.2092,0.0862,0.0927,0.0887)^{\tau} \\
19,11,30,26\end{array}$ \\
\hline 10th & $\begin{array}{l}\text { Order parameter } \\
\text { G } \\
\text { 1.2.1.1.1.1.1.1.1.1( } \\
\text { MG) }\end{array}$ & $\begin{array}{l}2 w_{2}=(0.1137,0.0984,0.0988,0.1731,0.1330,0.2735,0.1092)^{\tau} \\
19,30,26\end{array}$ \\
\hline 11th & $\begin{array}{l}\text { Order parameter } \\
\text { G } \\
\text { 1.2.1.1.1.2.1.2.2. } \\
\text { 1(MG) }\end{array}$ & $\begin{array}{l}2 w_{1}=(0.1429,0.1429,0.1429,0.1429,0.1429,0.1429,0.1429)^{\tau} \\
19,26\end{array}$ \\
\hline
\end{tabular}

( $\mathrm{G}$ refers to enterprise group. $\mathrm{MG}$ is an abbreviation of mainstream group.)

\subsection{Structural Feature of Industry}

As can be seen from TABLE IV, the industry is composed of 11 layers, in which all the companies are distributed in the corresponding layers and enterprise groups according to the value parameter structure of their individual advantage characteristics. For example, LC4 belongs to G1 (MG) at the first layer, and exists outside the groups at the second layer. At the first layer,
LC3 also belongs to G1, but its distribution features in the lower layers are different from LC4, i.e., it is in G1.2 at the second layer, G1.2.1 at the third layer and G1.2.1.1 at the fourth layer. These groups are MGs of corresponding systems. The company belongs to G1.2.1.1.2 at the fifth layer, which is a non-mainstream group of system. In fact, the two companies are very different in the value parameter structure. LC3 generally pursues a relatively balanced developing mode which would have been attached greater importance to $w_{5}$ and 
$w_{4}$. But LC4 has an absolute advantage in $w_{2}$ and $w_{3}$, which is very different from most companies in the industry (see TABLE II). Through the comparative analysis of these two companies in industrial structure, it is possible to get the findings as follows: (1) the higher the similarity of an enterprise to other enterprises in value structure, the greater its distribution extent in industrial structure; (2) the group's formation between enterprises in lower layer has stricter requirements on the similarity of value structure than that in upper layer; (3) the enterprises in a group will be the closest partners, for example, LC29 and LC37 at the first layer will be the closest partners under their common values.

\subsection{Relationship between the composition of enterprise group or the composition of enterprises in group and the performance}

The MG of industry, including 37 companies, belongs to advantageous group, of which LC12, LC36, LC4, LC25, LC3, LC18, LC38 can be considered as the advantageous enterprises (see TABLE III). Figure 2 describes the situation of performance of the entire industry, MG, the advantageous companies in MG, LC4 and LC3 in five financial indices.

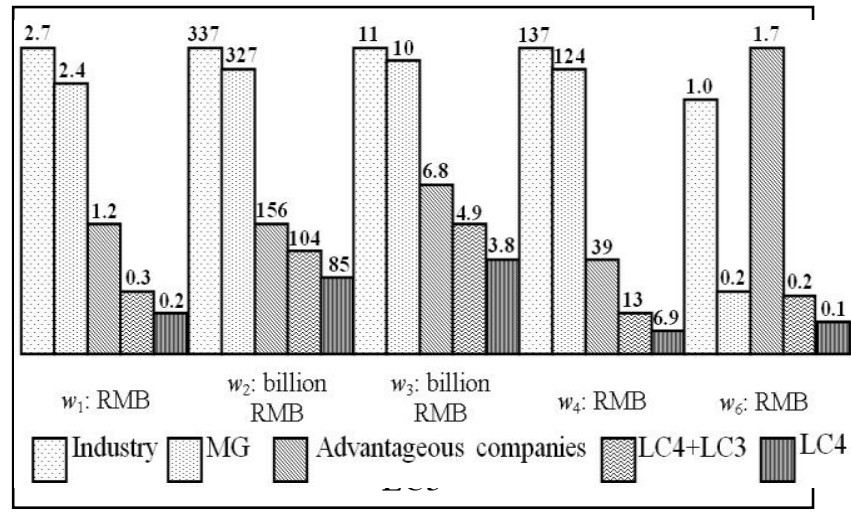

It can be seen from Figure 2 that the listed companies in MG take up the majority of performance of industry in terms of $w_{1}, w_{2}, w_{3}$ and $w_{4}$, in particular, the seven advantageous companies, including LC4 and LC3, have high abilities in $w_{2}$ and $w_{3}$. The MG appears inferior in $w_{6}$, while the advantageous companies have an absolute advantages. Based on the above analysis, it is possible to get the findings as follows: (1) the industry is in the growth stage of its development, because most of companies, taking dominant positions in $G_{R}^{*}$, belong to the MG of industry, which is more favorable for the development of industry and makes it possible to predict better business performance; (2) the companies in $\mathrm{MG}$ can also use the opportunity that their group is leading the development of industry to increase their abilities to the level of advantageous companies as soon as possible. LC12, LC36, LC4, LC25, LC3, LC18, LC38 are patterns for other listed companies in MG.

\subsection{Main developing mode of industry}

As can be seen from TABLE IV, there will be an order parameter to lead the development of system corresponding to it in each layer of industrial structure. Therefore, it is possible to understand the main developing mode of industry or system by analyzing the value structure of the order parameter, that is, it can be found that the industry has pursued a relatively balanced developing mode which would have been attached greater importance to $w_{5}, w_{4}$ and $w_{7}$, while the other systems basically put greater importance to $w_{5}$ and $w_{6}$. .

\section{CONCLUSION}

It is possible to obtain such useful information about the structural feature of Chinese iron and steel through the study in this paper as the distributive feature of enterprise groups in industry, the relationship between the distribution of listed companies and value structure, the main developing mode of industry, the benchmarks and partners and the relationship between enterprise group or its composition and performance, which is of great significance in the development of industrial economic theory as well as the practice of modern strategic management. However, there are still some lacks: for example, it is not sufficient to explain the essential and dynamic feature of corporate strategic behavior, the strategic position of enterprise in industry, etc.

Jingyou behavior is a driving force for the development of enterprise as well as industry, by which it is possible to solve some problems resulting from vicious competition. It further needs to carry out more comprehensive study on the Jingyou theory and its application in order to establish the industrial economy and strategic management theory based on the new value ideology of sustainable development era.

\section{Acknowledgement}

This research is financially supported by the National Science Council of the Republic of China (71271048).

\section{REFERENCES}

[1] Gilbert Faccarello, and D. Kurz. Heinz, Handbook on the History of Economic Analysis III, Edward Elgar Publishing, 2016.

[2] Porter, M, "The five competitive forces that shape strategy," Harvard Business Review, vol. 1, pp. 7994, 2008.

[3] Porter. M, Competitive advantage: creating and sustaining superior performance, The Free Press, 1985.

[4] Hunt. M, Competition in the Major Home Appliance Industry, Harvard University, 1972.

[5] James Hoyta, and Hugh Sherman, "Strategic groups, exit barriers and strategy decision constraints in high-tech companies," Journal of High Technology Management Research, vol. 15, pp. 237-247, 2004. 
[6] Michał Pietrzak, and Piotr Pietrzak, "Mapping strategic groups in higher education: Evidence on the Polish technical faculties," Journal of Applied Knowledge Management, vol. 5, pp. 1-15, 2017.

[7] Scott Sonenshein, Kristen Nault, and Otilia Obodaru, "Competition of a different flavor: how a strategic group identity shapes competition and cooperation,"
Administrative Science Quarterly, vol. 62, pp. 626656, 2017.

[8] Moore. F, The Death of Competition: Leadership and Strategy in the Age of Business Ecosystems, New York: Harper Business, 1996.

[9] Xinan Zhao, Chunhong Zhu, and Yanmei Wang, Jingyou Evaluation Theory, Method and Application, Science Publishing House, 2012. 